\title{
CFD-PBE simulation of gas-phase hydrodynamics in a gas-liquid-solid combined loop reactor
}

\author{
Qi Nana ${ }^{1}$, Zhang Kai ${ }^{*}$, Xu Gang ${ }^{1}$, Yang Yongping ${ }^{1}$ and Zhang $\mathrm{Hu}^{2}$ \\ ${ }^{1}$ School of Energy Power and Mechanical Engineering, North China Electric Power University, Beijing 102206, China \\ ${ }^{2}$ School of Chemical Engineering, University of Adelaide, South Australia, SA 5005, Australia \\ (C) China University of Petroleum (Beijing) and Springer-Verlag Berlin Heidelberg 2013
}

\begin{abstract}
The computational fluid dynamics (CFD)-population balance equations (PBE) coupled model is employed to investigate the hydrodynamics in a gas-slurry internal loop reactor with external slurry circulation. The predicted radial profiles of local gas holdup and bubble diameter are in good agreement with the corresponding experimental data. The spatio-temporal velocity profile of the gas phase reveals that the upward movement of gas is slowed down and the residence time of gas is prolonged by the downward momentum of the slurry. Introduction of the external slurry can greatly improve the uniformity of gas holdup distribution in the reactor, especially in the downcomer-tube action region. Moreover, the interaction between the downward slurry and upward gas can lead to small bubble size and high interfacial area as well as good mass and heat transfer. The above results suggest the function of external slurry circulation for the internal loop reactor and would be helpful for optimizing the design and scale up of reactors.
\end{abstract}

Key words: CFD-PBE simulation, external slurry circulation, gas-liquid-solid, hydrodynamics, population balance model

\section{Introduction}

As a modified three-phase fluidized-bed reactor, the loop reactor has been widely used in chemical processing and other related tasks due to its simple construction without moving parts, good mass and heat transfer behavior, efficient mixing with low energy consumption, straightforward operation with low cost and so on (Lo and Hwang, 2003; Vial et al, 2005; Giovannettone et al, 2009; Deng et al, 2010). The loop reactor is usually divided into external and internal loop reactors (Kilonzo and Margaritis, 2004; Wang et al, 2007). As shown in Fig.1a, the internal loop reactor is usually constructed by mounting a draft tube inside the fluidized bed. Liquid (or slurry) is brought up by gas sparged into the draft tube or the annulus region and falls down due to gravity, which results in overall liquid (or slurry) circulation in the reactor. The external loop reactor has an external downcomer attached to the fluidized bed. Gas is dispersed at the bottom of the riser and a global liquid (or slurry) circulation is induced due to the pressure difference between the riser and downcomer (Fig.1b).

Although liquid (or slurry) circulation in the both loop reactors can enhance mixing and improve heat and mass transfer between gas and liquid (or slurry) phases, the driving force arising from the pressure difference in an external loop reactor cannot be flexibly adjusted, and mass or heat transfer

*Correspinding author. email: zhangk98@yahoo.com

Received September 12, 2012 between gas and liquid (or slurry) in an internal loop reactor is slightly improved limitedly as gas flows co-currently with slurry. Therefore, several modified configurations of loop reactors were proposed to meet the requirement for slow chemical reactions, such as Fischer-Tropsch and methanol syntheses (Zhang and Zhao, 2006; Lu et al, 2009; Zhang et al, 2003, 2010b; Liu et al, 2008). Among these reactors, the combined gas-liquid (or -slurry) loop reactor proposed by Lu et al (2009) makes use of the advantages of the external and internal loop reactor. It includes a liquid (or slurry) spray section in the upper part, a sieve plates section in the middle part, and an internal loop section in the lower part. External liquid (or slurry) circulation is introduced by a downcomer tube (Fig.1c), which can enhance the driving force because of the pressure difference between the riser and the annular region and increase the interfacial area between the gas and liquid (or slurry) phases.

In this combined gas-liquid-solid three-phase loop reactor, gas-phase properties, such as gas holdup, bubble movement characteristics and bubble size distribution strongly affect heat and mass transfer and chemical reactions. Although gasphase properties have been investigated experimentally in the traditional internal loop reactors or bubble columns by many researchers (Jin et al, 2005, 2007; Zhang et al, 2008), little research has been carried out on combined loop reactors. In order to efficiently design and scale up this kind of reactor for liquid fuel synthesis using fine catalyst particles, a thorough understanding is needed of the hydrodynamics resulting in 


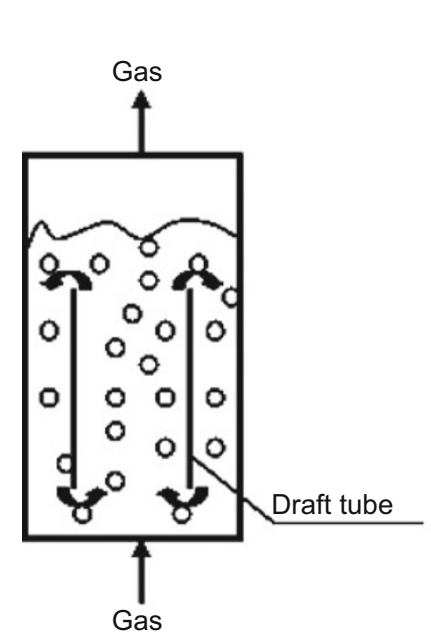

(a) Internal loop reactor

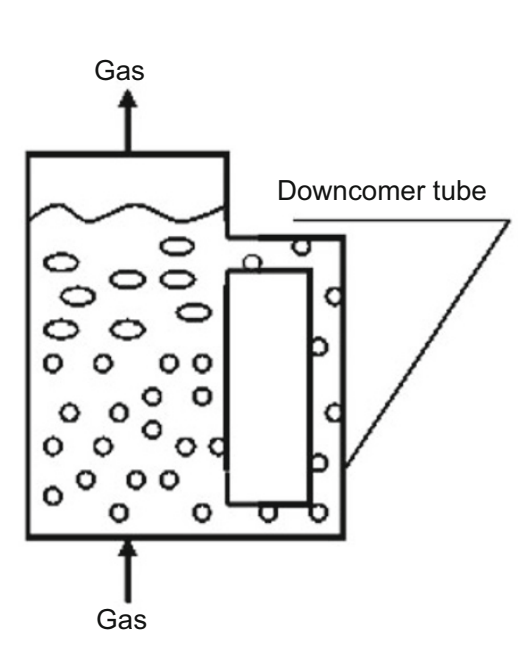

(b) External loop reactor

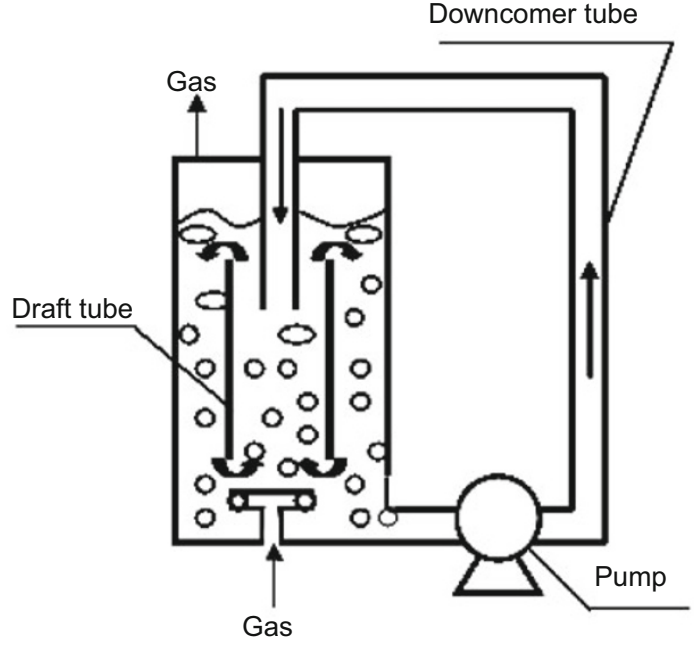

(c) Combined loop reactor

Fig. 1 Schematic diagram of the internal, external and combined loop reactor

the complex phenomena within the multiphase contactor. In recent decades, the significant improvement in design capability and reliability of multiphase reactors is mainly attributed to the advances in computational fluid dynamics (CFD) simulation. This technique can provide in-depth details about the fluid flow without conducting time-consuming and expensive experiments (Krishna et al, 2000; Jia et al, 2007; Bhole et al, 2008; Zhang et al, 2010a; Qi et al, 2011).

For most studies dealing with gas-liquid and gas-liquidsolid flows, all the bubbles are assumed to be the same size, i.e. monodisperse gas bubbles (van Baten and Krishna, 2001; Lu et al, 2009; Qi et al, 2011). In fact, a wide range of bubble sizes and shapes exist at different locations throughout the dispersed gas-liquid or gas-liquid-solid reactor, especially when superficial gas velocity is high. Bubbles with different sizes and shapes will result in the gas phase having velocity and volume fraction distributions. Meanwhile, these distributions will have an effect on the gas bubble sizes and shapes too. Currently, the multiple size group (MUSIG) model based upon the population balance model (PBM) has been widely used for predicting the dynamic bubble coalescence and breakup behavior in gas-liquid or gas-liquidsolid reactors (Jia et al, 2007; Bhole et al, 2008; Zhang et al, 2010a). The hydrodynamics and mass transfer have been investigated in the gas-liquid-solid internal loop reactor with external slurry circulation (Lu et al, 2009; Zhang et al, 2010b; Liu et al, 2007). The results show that experimental data are considerably affected by the fluid flow inside the reactor. To better understand the physical flow inside the complicated reactor, Lu et al (2009) ran CFD simulations with monodispersed gas bubbles in the gas-liquid reactor. Qi et al (2012) employed a CFD-PBE coupled model investigated the influence of reactor internals in a gas-liquid combined loop reactor. However, these simulations cannot capture the gas bubble characteristics for the slurry phase with different densities and viscosities in the gas-liquid-solid combined loop reactor. In this paper a CFD-PBE model is employed for further characterizing the flow dynamics, such as flow pattern, gas holdup and bubble diameter distribution in the internal loop reactor with external slurry circulation

\section{Mathematical model}

\subsection{Physical properties}

For the liquid fuel synthesis process, the fine catalyst particles are well mixed with the viscous liquid medium. Accordingly, the liquid phase and solid particles can be treated approximately as a pseudo-homogenous slurry phase. In this study, the correlations of Eq. (1) by Hillmer et al (1994) and Eq. (2) by Thomas (1965) are used, and they have been widely used for calculation of effective density and viscosity for a gas-slurry flow (Li and Prakash 1997; Iliuta et al, 2008):

$$
\begin{aligned}
& \rho_{\text {slurry }}=\frac{\alpha_{1} \rho_{1}+\alpha_{\mathrm{s}} \rho_{\mathrm{s}}}{\alpha_{1}+\alpha_{\mathrm{s}}} \\
& \mu_{\text {slurry }}=\mu_{1}\left(1+2.5 \alpha_{\mathrm{s}}+10.05 \alpha_{\mathrm{s}}^{2}+0.00273 e^{16.6 \alpha_{\mathrm{s}}}\right)
\end{aligned}
$$

where $\rho$ is the density, and $\alpha$ is the volume fraction. The subscript "l, s and slurry" stand for liquid, solid and slurry phases, respectively.

\subsection{Continuity and momentum equations}

An Eulerian-Eulerian multi-fluid model is employed, and both gas and slurry phases are treated as continuum, interpenetrating and interacting with each other in the computational domain. The pressure field is assumed to be shared by the both phases, which is in proportion to their corresponding volume fraction. The mass and momentum conservation equations are as below.

The continuity equation is:

$$
\frac{\partial\left(\alpha_{i} \rho_{i}\right)}{\partial t}+\nabla \cdot\left(\alpha_{i} \rho_{i} \vec{u}_{i}\right)=0
$$


where $u$ is the velocity, the subscript $i$ stands for gas or slurry phase.

The momentum equation is:

$$
\begin{aligned}
& \frac{\partial\left(\alpha_{i} \rho_{i} \vec{u}_{i}\right)}{\partial t}+\nabla \cdot\left(\alpha_{i} \rho_{i} \vec{u}_{i} \vec{u}_{i}\right) \\
& =-\alpha_{i} \nabla P_{i}+\nabla \cdot\left(\alpha_{i} \mu_{i}\left(\nabla \vec{u}_{i}+\left(\nabla \vec{u}_{i}\right)^{T}\right)\right)+\vec{F}_{i}+\alpha_{i} \rho_{i} \vec{g}
\end{aligned}
$$

where $P, \mu$, and $g$ are pressure, dynamic viscosity and gravity acceleration, respectively. $F_{i}$ is the interfacial force acting on phase $i$ as the presence of the other phase, $j$, including drag force, interphase turbulent dispersion force, virtual mass force and lift force. The virtual mass force and lift force are negligible in comparison to the drag force and interphase turbulent disperion force (Panneerselvam et al, 2008; Bartrand et al, 2009), then $F_{i}$ can be expressed as:

$$
\vec{F}_{i}=\vec{F}_{i}^{\mathrm{D}}+\vec{F}_{i}^{\mathrm{T}}
$$

where $F_{i}{ }^{\mathrm{D}}$ is the drag force, and $F_{i}^{\mathrm{T}}$ is the interfacial force resulting from turbulent dispersion. by:

The drag component of the interfacial force term is given

$$
\vec{F}_{i}^{\mathrm{D}}=\frac{C_{\mathrm{D}}}{8} A_{i j} \rho_{i}\left|\vec{u}_{j}-\vec{u}_{i}\right|\left(\vec{u}_{j}-\vec{u}_{i}\right)
$$

where $C_{\mathrm{D}}$ is the drag force coefficient, $A_{i j}$ is the net interfacial area between the two phases. The Grace model proposed by Cift et al (1978) is chosen for calculating the drag force, and the drag force coefficient is:

$$
C_{D}=\frac{4}{3} \frac{g d_{\mathrm{b}}}{u_{\mathrm{T}}^{2}} \frac{\Delta \rho}{\rho_{\text {slurry }}}
$$

where $d_{\mathrm{b}}$ stands for the mean bubble diameter, $\Delta \rho$ is the difference of density between the slurry and gas phases, $u_{\mathrm{T}}$ is the bubble terminal rise velocity, which can be calculated as:

$$
u_{\mathrm{T}}=\frac{\mu_{\text {slurry }}}{\rho_{\text {slurry }} d_{\mathrm{b}}} M^{-0.149}(J-0.857)
$$

where $M$, Morton number (a fluid property), is formulated as:

$$
M=\frac{\mu_{\text {slury }}^{4} g \Delta \rho}{\rho_{\text {slurry }}^{2} \sigma^{3}}
$$

and $J$ is given by:

$$
\begin{array}{ll}
J=0.94 H^{0.751}, & 2<H \leq 59.3 \\
J=3.42 H^{0.441}, & H>59.3
\end{array}
$$

and $H$ is calculated as:

$$
H=\frac{4}{3} E \ddot{0} M^{-0.149}\left(\frac{\mu_{\text {slurry }}}{\mu_{\text {ref }}}\right)^{-0.14}
$$

where $\sigma$ is the surface tension, $\mu_{\text {ref }}$ is the molecular viscosity of tap water at a reference temperature and pressure, and $E \ddot{o}$, Eötvös number, is expressed as below:

$$
E \ddot{O}=\frac{g \Delta \rho d_{\mathrm{b}}^{2}}{\sigma}
$$

The turbulent dispersion force $\left(F_{i}^{\mathrm{T}}\right)$ is calculated by the Lopez de Bertodano model (1991):

$$
\vec{F}_{i}^{\mathrm{T}}=C_{\mathrm{TD}} C_{\mathrm{D}} \frac{v_{\text {tslurry }}}{\sigma_{\text {tslurry }}}\left(\frac{\nabla \alpha_{g}}{\alpha_{g}}-\frac{\nabla \alpha_{\text {slurry }}}{\alpha_{\text {slurry }}}\right)
$$

where $C_{\mathrm{TD}}$ is the momentum transfer coefficient for the interphase drag force, which ranges from 0.1 to 0.5 based on the superficial gas velocity; $C_{\mathrm{D}}$ is the drag force coefficient; $v_{\text {tslury }}$ stands for turbulent viscosity and $\sigma_{\text {tslurry }}$ for the turbulent Schmidt number of the slurry phase.

\subsection{Turbulence model}

In order to solve the Reynolds stress in the turbulent momentum equations, the standard $k-\varepsilon$ model is chosen for simulating the slurry phase, and expressed as follows:

$$
\begin{aligned}
& \frac{\partial}{\partial t}\left(\alpha_{\text {slurry }} \rho_{\text {slurry }} k\right)+\nabla \cdot\left(\alpha_{\text {slurry }} \rho_{\text {slurry }} \vec{u}_{\text {slurry }} k\right) \\
& =\nabla \cdot\left[\alpha_{\text {slurry }}\left(\mu_{\text {slurry }}+\frac{\mu_{\text {tslurry }}}{\sigma_{k}}\right) \nabla k\right]+\alpha_{\text {slurry }} P_{\text {slurry }}-\alpha_{\text {slurry }} \rho_{\text {slurry }} \varepsilon
\end{aligned}
$$

$$
\begin{aligned}
& \frac{\partial}{\partial t}\left(\rho_{\text {slurry }} \alpha_{\text {slurry }} \varepsilon\right)+\nabla \cdot\left(\alpha_{\text {slury }} \rho_{\text {slurry }} \vec{u}_{\text {slury }} \varepsilon\right) \\
& =\nabla \cdot\left[\alpha_{\text {slurry }}\left(\mu_{\text {slurry }}+\frac{\mu_{\text {tslurry }}}{\sigma_{\varepsilon}}\right) \nabla \varepsilon\right]+\alpha_{\text {slurry }} \frac{\varepsilon}{k}\left(C_{\varepsilon 1} P_{\text {slurry }}-C_{\varepsilon 2} \rho_{\text {slurry }} \varepsilon\right)
\end{aligned}
$$

where $C_{\varepsilon 1}, C_{\varepsilon 2}, \sigma_{k}$, and $\sigma_{\varepsilon}$ are parameters in the standard $k-\varepsilon$ model and the following values are selected: $C_{\varepsilon 1}=1.44, C_{\varepsilon 2}$ $=1.92, \sigma_{k}=1.0$, and $\sigma_{\varepsilon}=1.3$ (ANSYS, 2005). The turbulent viscosity of the slurry phase is modeled using the Sato enhanced turbulence model (Sato and Sadatomi, 1981), as the following equation:

$$
\mu_{\text {tslurry }}=\mu_{t \text { slurry,s }}+\mu_{\text {tslurry, } \mathrm{b}}
$$

where $\mu_{t s l u r r y, s}$ represents the conventional shear-induced turbulent viscosity and is obtained by the standard $k-\varepsilon$ model as:

$$
\mu_{\text {tslury }, \mathrm{s}}=C_{\mu} \rho_{\text {slury }} \frac{k^{2}}{\varepsilon}
$$

$C_{\mu}$ is a constant, which is 0.09 (ANSYS, 2005), and $\mu_{\text {tslurry,b }}$ is a bubble-induced component of turbulent viscosity given by:

$$
\mu_{\text {tslurry }, \mathrm{b}}=C_{\mu, \mathrm{b}} \rho_{\text {slurry }} \alpha_{g} d_{\mathrm{b}}\left|\vec{u}_{g}-\vec{u}_{\text {slurry }}\right|
$$

The zero equation model has been proved and utilized to simulate the dispersed phase (gas or solid) turbulence in twoor three-phase reactors (Díaz et al, 2008; Panneerselvam et al, 2008; Bartrand et al, 2009). This model is used to calculate 
the turbulent viscosity of the gas phase in this study.

$$
\mu_{t g}=\frac{\rho_{g}}{\rho_{\text {slurry }}} \frac{\mu_{\text {tslurry }}}{\sigma_{t}}
$$

where $\sigma_{t}$ is a turbulent Prandtl number relating the gas phase kinematic eddy viscosity $\left(\mu_{\mathrm{tg}}\right)$ to the kinematic eddy viscosity of slurry phase $\left(\mu_{t \text { slurry }}\right)$.

\subsection{MUSIG model}

The Multiple Size Group (MUSIG) model based on the gas bubble population model is employed to handle polydispersed bubbles in the simulation. One attribute of polydispersed multiphase flow is that different sizes of the dispersed phase interact with each other through the mechanisms of breakup and coalescence (Bhole et al, 2008; Zhang et al, 2010b). This MUSIG model considers several bubble classes with different diameters $\left(d_{i}\right)$, which can be represented by an equivalent phase with a Sauter mean diameter $\left(d_{\mathrm{b}}\right)$. Let $n(m, t)$ stand for the number density of gas bubbles of mass $m$ at time $t$, population balance equations can be expressed as:

$$
\frac{\partial n(m, t)}{\partial t}+\nabla \cdot(u(m, t) n(m, t))=B_{\mathrm{B}}-D_{\mathrm{B}}+B_{\mathrm{C}}-D_{\mathrm{C}}
$$

where $B_{\mathrm{B}}, D_{\mathrm{B}}, B_{\mathrm{C}}$, and $D_{\mathrm{C}}$ are the birth rate as the breakup of larger bubbles, the death rate as the breakup of larger bubbles into smaller bubbles, the birth rate as the coalescence of smaller bubbles, and the death rate as the coalescence of smaller bubbles with other bubbles, respectively. These rates may further be expressed as:

$$
\begin{aligned}
& B_{\mathrm{B}}=\int_{m}^{\infty} g(\varepsilon ; m) n(\varepsilon, t) \mathrm{d} \varepsilon \\
& D_{\mathrm{B}}=n(m, t) \int_{0}^{m} g(m ; \varepsilon) \mathrm{d} \varepsilon \\
& B_{\mathrm{C}}=\frac{1}{2} \int_{0}^{m} Q(m-\varepsilon ; \varepsilon) n(m-\varepsilon, t) n(m, t) \mathrm{d} \varepsilon \\
& D_{\mathrm{C}}=n(m, t) \int_{0}^{\infty} Q(m ; \varepsilon) n(\varepsilon, t) \mathrm{d} t
\end{aligned}
$$

where $g(m ; \varepsilon)$ stands for the specific breakup rate, and $Q(m ; \varepsilon)$ for the specific coalescence rate.

The above Eq. (21) is discretized into 10 size-groups in this study. Let $N_{i}$ denotes the number density of size group $i$ :

$$
N_{i}(t)=\int_{m_{i-1 / 2}}^{m_{i+1 / 2}} n(m, t) \mathrm{d} m
$$

Define the mass and volume fraction of size group $i$ are $m_{i}$ and $\alpha_{i}$, respectively, and recognize that $m_{i} N_{i}$ is equal to $\rho_{i} \alpha_{i}$, Eq. (21) can be integrated over the group size dimension and multiply by $m_{i}$ to give:

$$
\frac{\partial\left(m_{i} N_{i}(t)\right)}{\partial t}+\frac{\partial}{\partial x^{i}}\left(U_{i}^{i}(t) N_{i}(t)\right)=S_{i}
$$

or:

$$
\frac{\partial\left(\rho_{i} \alpha_{i}\right)}{\partial t}+\frac{\partial}{\partial x^{i}}\left(\rho_{i} \alpha_{i} U_{i}^{i}\right)=S_{i}
$$

where $U_{i}$ is velocity of size group $i$. and $S_{i}$ is source term of size group $i$ which is:

$$
S_{i}=B_{\mathrm{B}}-D_{\mathrm{B}}+B_{\mathrm{C}}-D_{\mathrm{C}}
$$

Defining the size fraction $f_{i}=\alpha_{i} / \alpha_{g}$, Eq.(28) can be written as:

$$
\frac{\partial}{\partial t}\left(\rho_{i} \alpha_{g} f_{i}\right)+\frac{\partial}{\partial x^{i}}\left(\rho_{i} \alpha_{g} U_{i}^{i} f_{i}\right)=S_{i}
$$

Eq. (29) is the size fraction equation used by the MUSIG model. A further simplification assumes that all the size groups share the same density $\rho_{g}$ and velocity $U_{g}$, yielding the homogeneous MUSIG model:

$$
\frac{\partial}{\partial t}\left(\rho_{g} \alpha_{g} f_{i}\right)+\frac{\partial}{\partial x^{i}}\left(\rho_{g} \alpha_{g} U_{g}^{i} f_{i}\right)=S_{i}
$$

In the homogeneous MUSIG model, the birth rate of small bubbles resulting from the breakup of larger bubbles, is contributed to the source term, $S_{i}$, and it is calculated as:

$$
B_{\mathrm{B} i}=m_{i} \int_{m_{i-1 / 2}}^{m_{i+1 / 2}} B_{\mathrm{B}} \mathrm{d} m=\rho_{g} \alpha_{g}\left(\sum_{j>i} g\left(m_{j} ; m_{i}\right) f_{j}\right)
$$

and the death rate of large bubbles by breaking into smaller bubbles is:

$$
D_{\mathrm{B} i}=\rho_{g} \alpha_{g}\left(f_{j} \sum_{j>1} g\left(m_{i} ; m_{j}\right)\right)
$$

The total source to breakup is zero when summed over all the size groups:

$$
\sum_{i}\left(B_{B i}-D_{B i}\right)=0
$$

For the discretized coalescence sources, the coalescence mass matrix, $X_{j k i}$, is defined as the fraction of mass which generates from coalescence between groups $j$ at time $t$ and distributes into group $i$ :

$X_{j k i}=\left\{\begin{array}{lll}\frac{\left(m_{j}+m_{k}\right)-m_{i-1}}{m_{i}-m_{i-1}} & \text { if } & m_{i-1}<m_{j}+m_{k}<m_{i} \\ \frac{m_{i+1}-\left(m_{j}+m_{k}\right)-m_{i-1}}{m_{i+1}-m_{i}} & \text { if } & m_{i}<m_{j}+m_{k}<m_{i+1} \\ 0 & \text { otherwise } & \end{array}\right.$

and the contribution of the birth rate due to the coalescence of smaller bubbles to the source term in Eq. (30) is:

$$
\begin{aligned}
& B_{\mathrm{C} i}=m_{i} \int_{m_{i-1 / 2}}^{m_{i+1 / 2}} B_{\mathrm{C}} \mathrm{d} m \\
& =m_{i}\left(\frac{1}{2} \sum_{j \leq i} \sum_{k \leq i} Q\left(m_{j} ; m_{k}\right) X_{j k i} N_{j} N_{k}\right. \\
& =\left(\rho_{g} \alpha_{g}\right)^{2}\left(\frac{1}{2} \sum_{j \leq i} \sum_{k \leq i} Q\left(m_{j} ; m_{k}\right) X_{j k i} f_{j} f_{k} \frac{m_{j}+m_{k}}{m_{j} m_{k}}\right)
\end{aligned}
$$


The contribution of the death rate due to coalescence of smaller bubbles into larger groups to the source term in Eq. (30) is:

$$
D_{\mathrm{C} i}=\left(\rho_{g} \alpha_{g}\right)^{2}\left(\sum_{j} Q\left(m_{i} ; m_{j}\right) f_{i} f_{j} \frac{1}{m_{j}}\right)
$$

This formulation for the coalescence source term guarantees that the total source to coalescence is zero when summed over all the size groups:

$$
\sum_{j}\left(B_{\mathrm{C} i}-D_{\mathrm{C} i}\right)=0
$$

This follows from the requirement that $Q\left(m_{i} ; m_{j}\right)$ is equal to $Q\left(m_{g} ; m_{i}\right)$, together with the following property of the mass matrix for all $j$ and $k$ :

$$
\sum_{j} X_{j k i}=1
$$

For the break-up of bubbles in turbulent dispersion, the theoretical model developed by Luo and Svendsen (1996) is employed. This model is developed based on the theories of isotropic turbulence and probability, and significantly it does not contain any unknown or adjustable parameters. Assuming that binary break-up occurs, the break-up rate of bubbles $m_{i}$ into bubbles $m_{j}\left(=f_{\mathrm{BV}} m_{i}\right)$ is expressed as:

$g\left(m_{i} ; f_{\mathrm{BV}} m_{i}\right)=0.923 F_{\mathrm{B}}\left(1-\alpha_{g}\right)\left(\frac{\varepsilon}{d_{i}^{2}}\right)^{1 / 3} \int_{\xi_{\min }}^{1} \frac{(1+\xi)^{2}}{\xi^{11 / 3}} e^{-\chi} \mathrm{d} \xi$

where $\xi$ is the dimensionless size of eddies in the inertial sub-range of isotropic turbulence, the coefficient $F_{\mathrm{B}}$ is added for calibration of the model. $x$ is the critical dimensionless energy for break-up, and $f_{\mathrm{BV}}$ is the breakup kernels. They are defined by:

$$
\begin{aligned}
& x=\frac{12\left(f_{\mathrm{BV}}^{2 / 3}+\left(1-f_{\mathrm{BV}}\right)^{2 / 3}-1\right) \sigma}{\beta \rho_{p} \varepsilon^{2 / 3} d_{i}^{5 / 3} \xi^{1 / 3}} \\
& f_{\mathrm{BV}}=\frac{m_{j}}{m_{i}}
\end{aligned}
$$

where $\beta$ is the coefficient set for 1.0 (Luo and Svendsen, 1996; Zhang et al, 2010a).

For the coalescence of two bubbles, the model of Prince and Blanch (1990) is used. It considers the collisions resulting from three different mechanisms, namely turbulence $\left(\theta_{i j}{ }^{T}\right)$, buoyancy $\left(\theta_{i j}{ }^{B}\right)$ and laminar shear $\left(\theta_{i j}{ }^{S}\right)$. So the total coalescence rate is:

$$
Q\left(m_{i} ; m_{j}\right)=\left(\theta_{i j}^{\mathrm{T}}+\theta_{i j}^{\mathrm{B}}+\theta_{i j}^{\mathrm{S}}\right) e^{-t_{i j} / \tau_{i j}}
$$

However, the contribution from laminar shear to collision frequency is far less than that from turbulence and buoyancy (Jia et al, 2007; Bhole et al, 2008), so such effect from laminar shear is neglected in this work.

\subsection{Numerical details}

As mentioned in the Introduction, the combined loop reactor is composed of three sections, i.e. a spray section, a sieve-plate section, and an internal loop section. Fig. 2 shows the physical configuration and mesh topology of the internal loop section. A hybrid mesh topology technique is employed in this study. An unstructured mesh is used to manage the lower part of the internal loop section to accommodate the complicated geometrical configuration of the gas distributor, while a structured mesh is used for the rest. More detailed information about the mesh topology technique can be found elsewhere (Lu et al, 2009).

Boundary conditions, initial conditions and the iteration scheme are set for the numerical simulation using the ANSYS CFX 10.0 software package (ANSYS, 2005). At the gas and slurry inlets, gas and slurry velocities are set according to experimental input. At the slurry outlet, gas velocity is set as zero whilst slurry velocity is assigned to be the same as the experimental data. At the gas outlet, a degassing boundary condition is employed at the free surface, from where dispersed bubbles are permitted to escape but the slurry phase is not allowed. Along the wall, gas and slurry are treated as free-slip and no-slip, respectively. Initial bubble size distribution in the MUSIG model is obtained from the experimental measurements by Zhang et al (2010b). In this work, ten bubble classes, with the diameter ranging from 0 to $8 \mathrm{~mm}$ at lower superficial gas velocities (Figs. 3a and $3 \mathrm{~b}$ ) or 0 to $22 \mathrm{~mm}$ at higher superficial gas velocities (Fig. 3c), are employed.

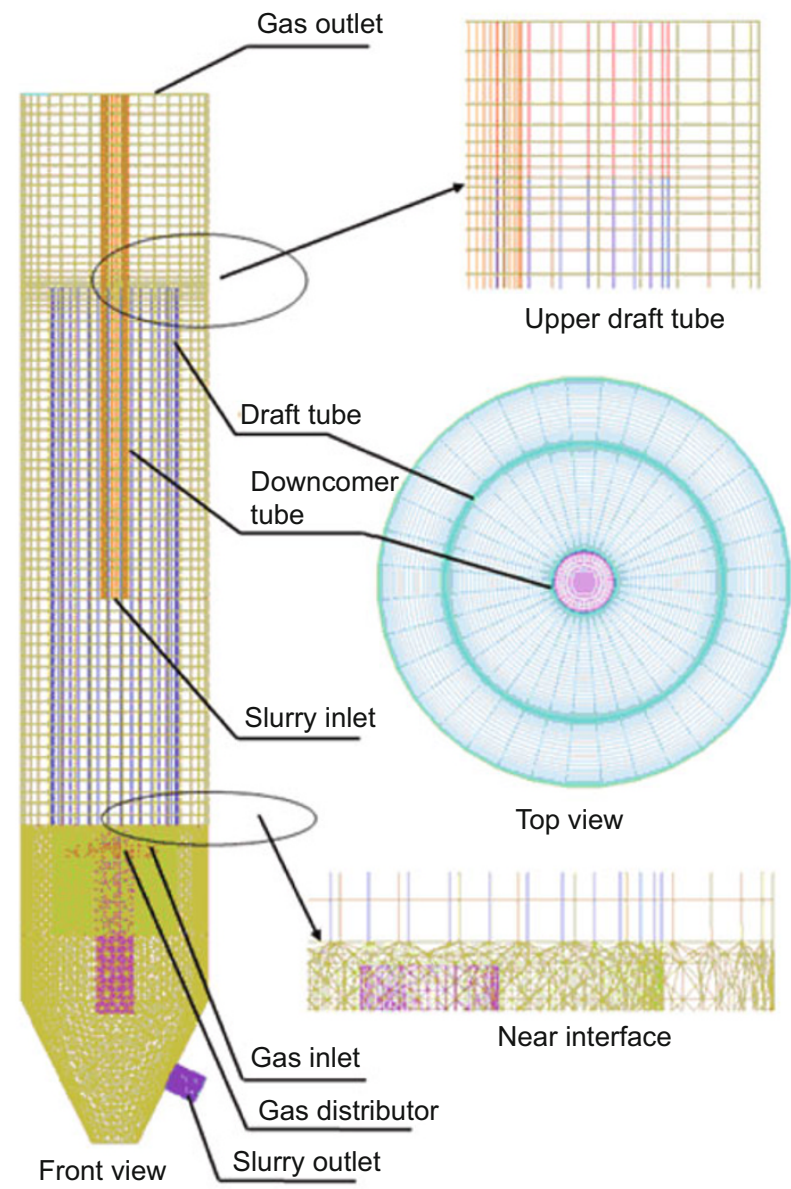

Fig. 2 Mesh topology of the combined loop reactor 


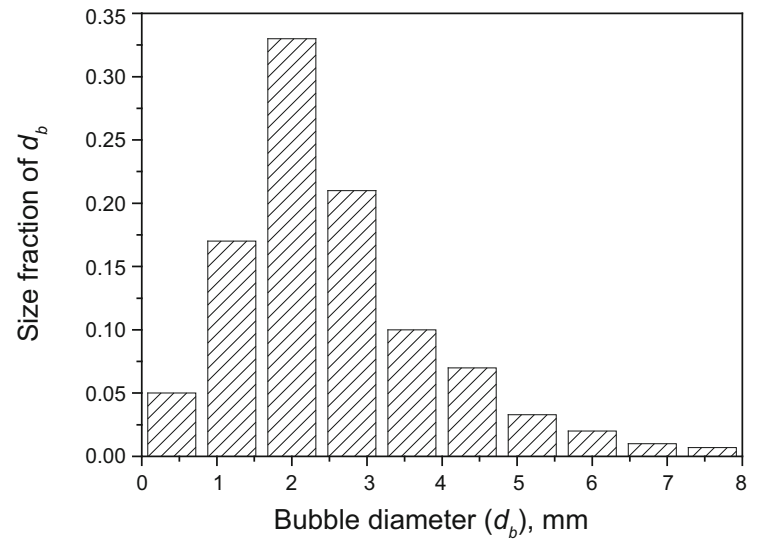

(a) $U_{g}=0.0059 \mathrm{~m} / \mathrm{s}$

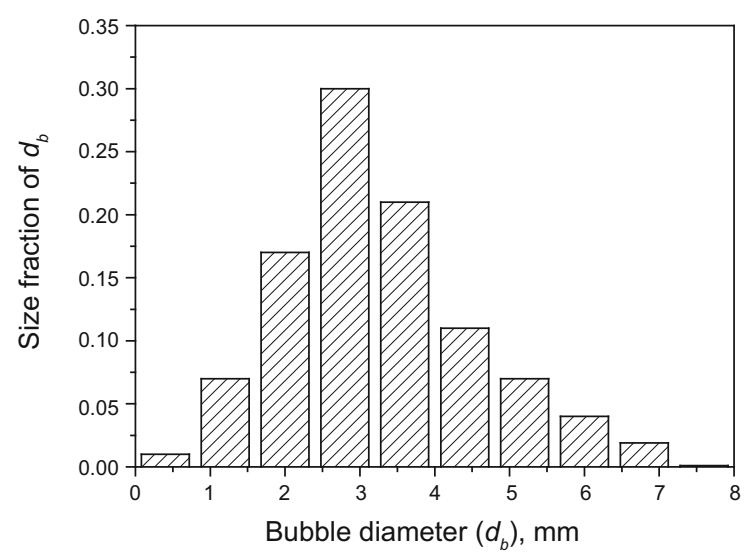

(b) $U_{\mathrm{g}}=0.0671 \mathrm{~m} / \mathrm{s}$

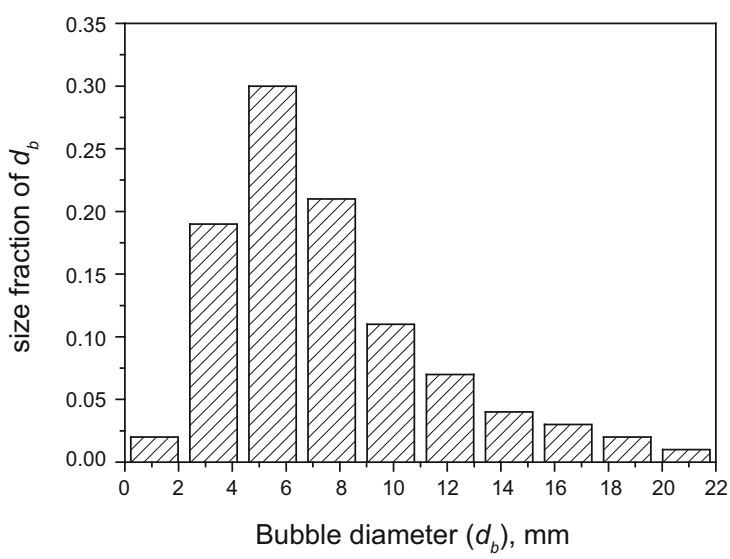

(c) $U_{g}=0.1895 \mathrm{~m} / \mathrm{s}$

Fig. 3 Measured bubble size distribution used for initial input of bubble size in the simulation

\section{Results and discussion}

The internal loop reactor is generally divided into four regions, namely the riser or draft tube region, the gas-liquid separator region, the annulus region and the bottom region (Talvy et al, 2005; Luo and Al-Dahhan, 2008). Two extra regions have to be considered after external slurry circulation is introduced ( $\mathrm{Lu}$ et al, 2009; Liu et al, 2008; Zhang et al, $2010 \mathrm{~b}$ ), and the combined loop reactor is then divided into six regions as shown in Fig. 4.

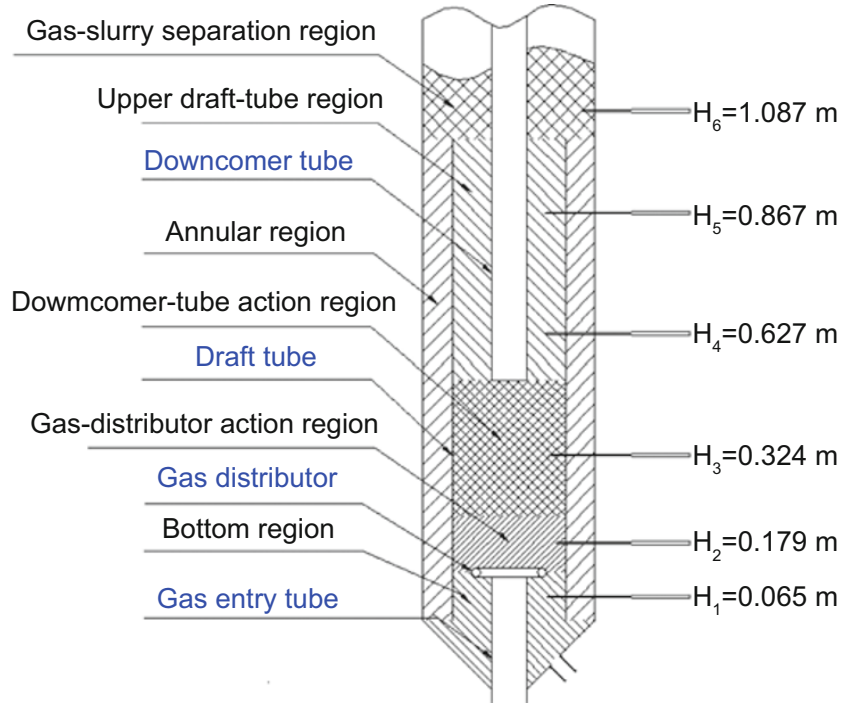

Fig. 4 Schematic diagram of regions and their axial positions for the combined loop reactor

\subsection{Model verification and validation}

In order to verify the reliability of the CFD model and accuracy of the numerical method, radial distribution of local gas holdup and bubble diameter are compared quantitatively with their corresponding experimental results. The detailed experimental procedure and data processing can be found in our previous paper (Zhang et al, 2010b). From Fig. 5, it can be seen that for majority of the reactor, the simulated gas holdups are in good agreement with the experimental data although there are deviations in the downcomer-tube action region.

The radial distribution of local mean bubble diameter in the downcomer-tube action region is shown in Fig. 6. It can be seen that for the majority of the reactor, simulated bubble diameters are in qualitative agreement with the experimental data although there are deviations at lower gas velocities $(0.0059 \mathrm{~m} / \mathrm{s}$ and $0.0671 \mathrm{~m} / \mathrm{s})$. The local mean bubble diameter increases with the increase of superficial gas velocity. Bubbles in the region (around $r / R=0.43$ ) above the gas jet nozzle is bigger than those near the reactor centre and draft tube wall. This is largely because high gas holdup (Fig. 5c) leading to a high coalescence rate.

\subsection{Flow pattern of the gas phase}

Gas holdup and bubble behaviour depends heavily on the prevailing flow pattern. As the slurry is introduced from the downcomer tube into the reactor, it can lead to more complicated fluid dynamics. Fig. 7 shows that when there is no slurry circulated into the draft tube (Fig. 7a), bubbles move upward with a relatively high velocity in the centre of the draft tube, quite similar to that in a traditional bubble column (Jin et al, 2007). When the slurry is introduced into the draft tube at a low velocity (Fig. 7b), the upward velocity of gas phase is slowed down by the downward momentum of the slurry phase. Gas bubbles rise upward along a distorted pathway near the bottom of the downcomer tube and are pushed towards the wall of the draft tube. When the 


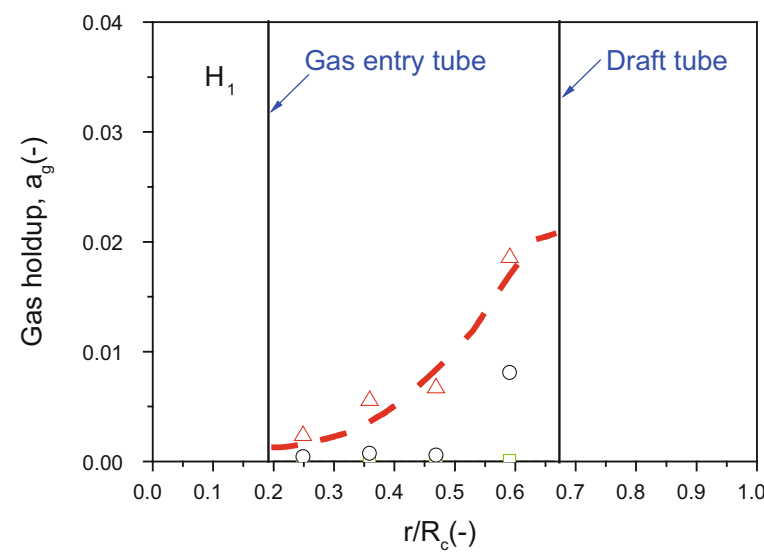

(a) Bottom region

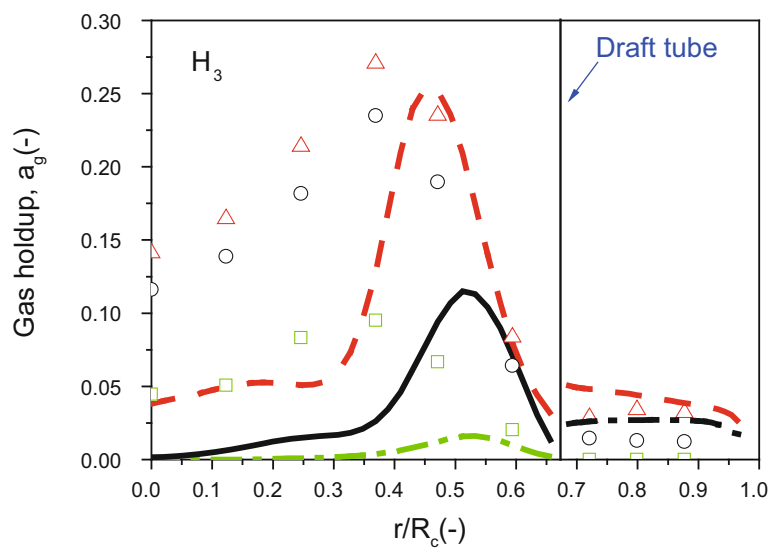

(c) Downcomer-tube action region

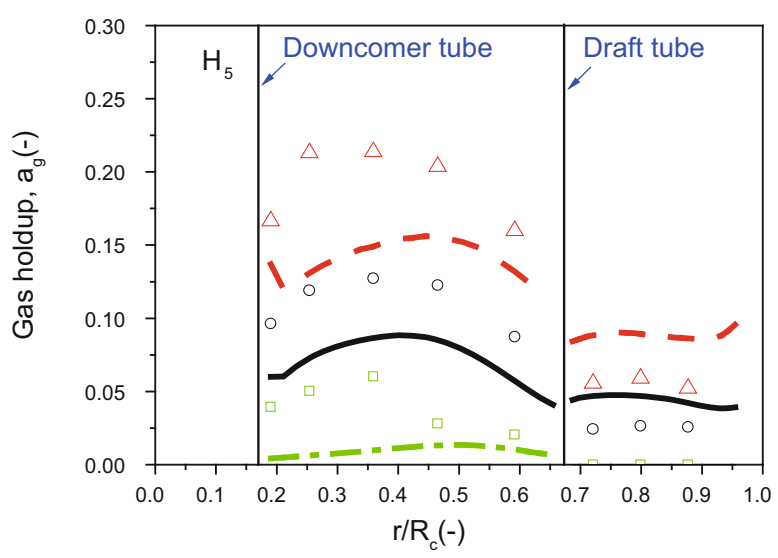

(e) Upper draft- tube region

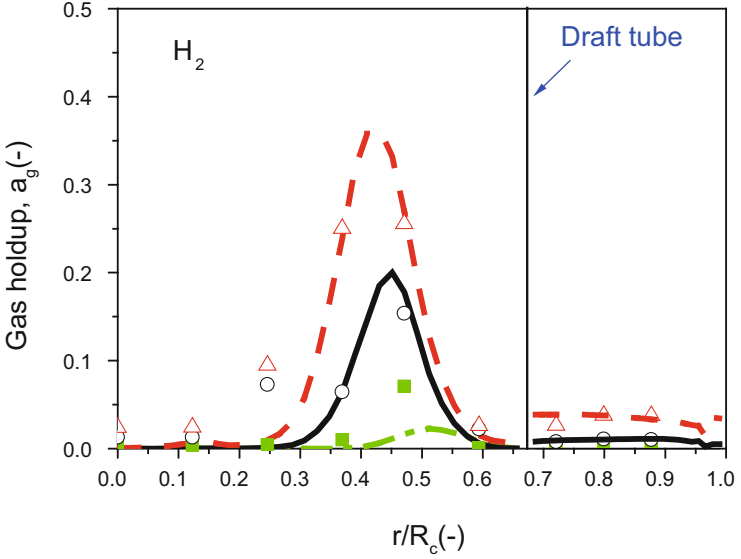

(b) Gas-distributor action region

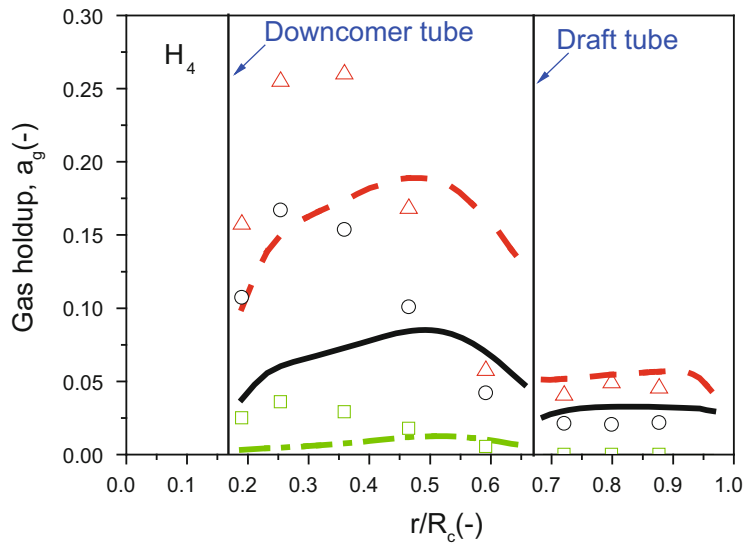

(d) Upper draft- tube region

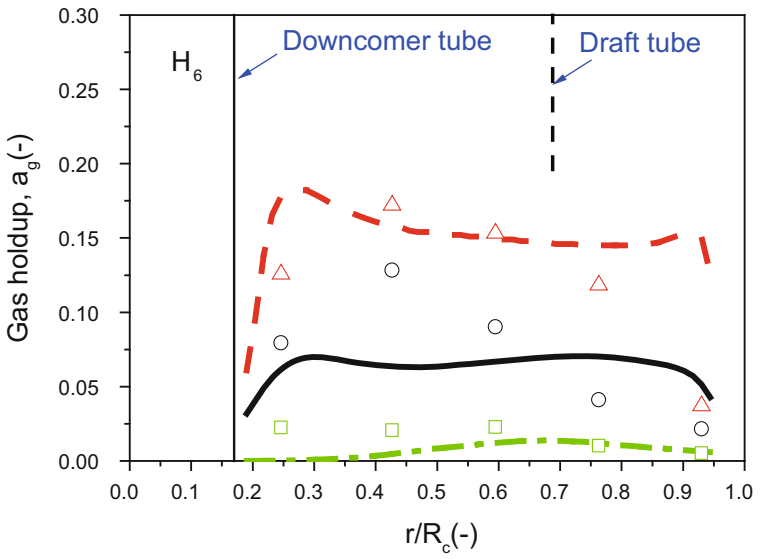

(f) Gas-slurry separation region

Experimental $U_{\mathrm{g}}(\mathrm{m} / \mathrm{s}): \square 0.0059, \circ 0.0671, \triangle 0.1895$

Simulated $U_{\mathrm{g}}(\mathrm{m} / \mathrm{s})$ : Dash dot line (green): 0.0059; Solid line: 0.0671; Dashed line (red): 0.1895

Fig. 5 Radial profiles of local gas holdup at different axial positions $\left(U_{\text {cir }}=0.05 \mathrm{~m} / \mathrm{s}\right)$

circulation velocity of the slurry is increased (Fig. 7c), gas bubbles rise upward on a distorted pathway just above the gas distributor as the slurry phase moves down at a rapid speed. Therefore, the rising pathway of bubbles increases with a decrease in bubble velocity, and counter-flow between the gas and slurry phases contribute to the increased gas holdup and mass transfer between the two phases.

\subsection{Gas holdup characteristics}

Fig. 8 shows that the gas holdup in the annular region is nearly zero and very few bubbles are recirculated by the downward fluid when the external slurry circulation velocity is $0 \mathrm{~m} / \mathrm{s}$. When the $U_{\text {cir }}$ is increased to $0.03 \mathrm{~m} / \mathrm{s}$ or $0.05 \mathrm{~m} / \mathrm{s}$, the gas holdup in the annular region is much higher than that when there is no external slurry introduction, indicating that more gas bubbles are retained in the annular region by the slurry from the gas-slurry separation region. Such simulated results indicate that the external slurry circulation by the downcomer tube can greatly increase the residence time of the gas phase and the number of bubbles interacting with the 


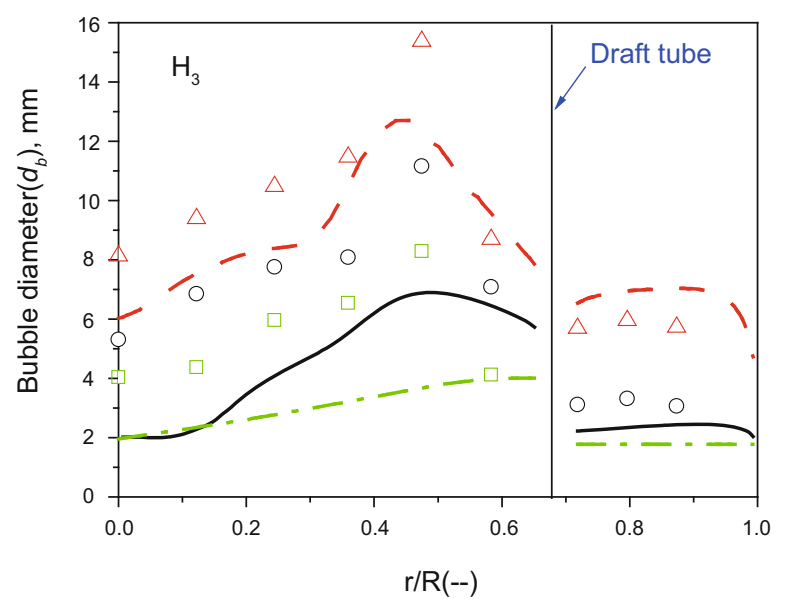

Experimental $U_{\mathrm{g}}(\mathrm{m} / \mathrm{s}): \square 0.0059, \circ 0.0671, \triangle 0.1895$

Simulated $U_{\mathrm{g}}(\mathrm{m} / \mathrm{s})$ : Dash dot line (green): 0.0059; Solid line: 0.0671; Dashed line (red): 0.1895

Fig. 6 Radial profiles of local bubble diameter in the downcomer-tube action region $\left(U_{\text {cir }}=0.05 \mathrm{~m} / \mathrm{s}\right)$ slurry phase, further enhancing the mass and heat transfer in the reactor.

The distribution of local gas holdup along the radial direction is shown in Fig. 9. Clearly, the introduction of external slurry has a minor impact on the gas holdup at the gas distributor region (Fig. 9a), and the peak location of gas holdup varies a little caused by the downward moving slurry phase in comparison with that of the original distributor. However, a significant increase in gas holdup can be found in the down-comer tube action region (Fig. 9b) when the external slurry phase is introduced into this region. Moreover, a high circulation velocity $(0.05 \mathrm{~m} / \mathrm{s})$ results in a low gas holdup in comparison with a circulation velocity of $0.03 \mathrm{~m} / \mathrm{s}$. This can be explained by the flow pattern shown in Fig. 7c.

\subsection{Bubble size distribution}

The multi-fluid model coupled with PBE produces the profile of gas bubble size distribution in the internal loop section (see Fig. 9). It can be seen that the gas bubble size distribution is different in different regions, even at a fixed
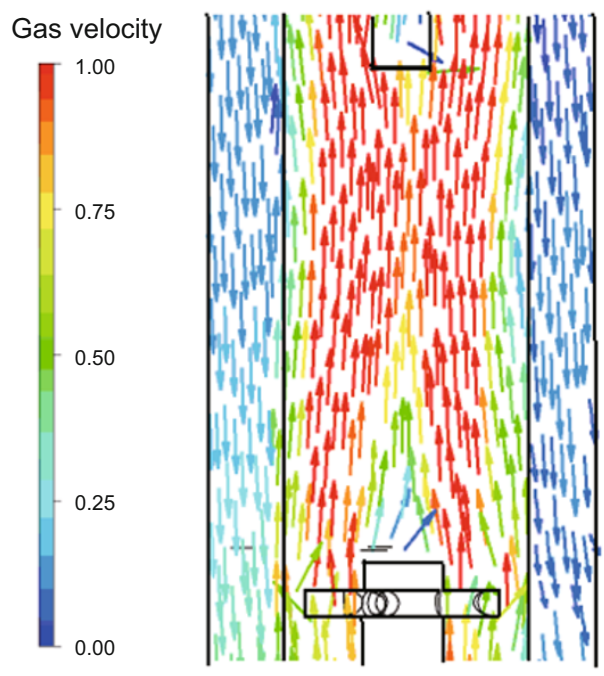

(a) $U_{\text {cir }}=0 \mathrm{~m} / \mathrm{s}$

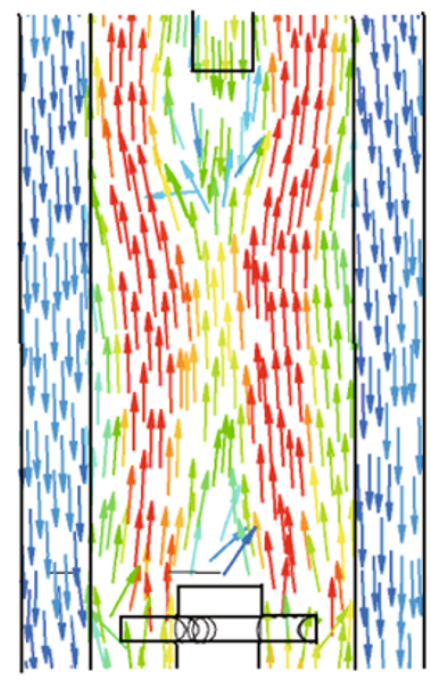

(b) $U_{\text {cir }}=0.03 \mathrm{~m} / \mathrm{s}$

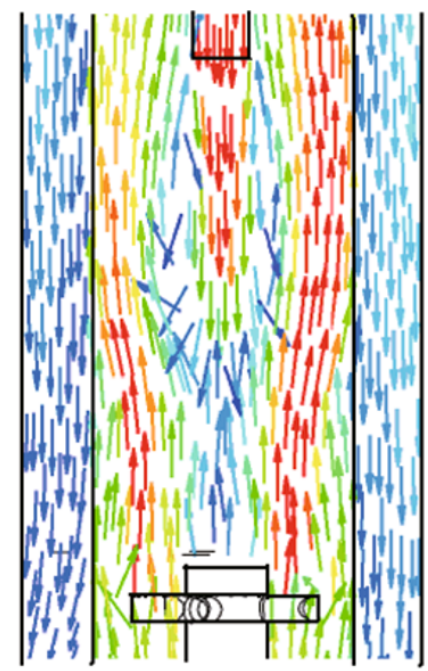

(c) $U_{\text {cir }}=0.05 \mathrm{~m} / \mathrm{s}$

Fig. 7 Gas velocity vectors between the downcomer tube and gas distributor at different slurry circulation velocities $(U \mathrm{~g}=0.1895 \mathrm{~m} / \mathrm{s})$

slurry circulation velocity. The vertical profile of gas bubble sizes at the three external slurry velocities in Fig. 10 shows that the smallest bubbles are found in the downcomer-tube action region because of the break-up of larger bubbles in the highly interactive stream (Fig. 7). Relatively small bubbles are found in the bottom region as large bubbles escape from the gas-slurry separation region. However, the relatively low gas holdup in the bottom region shown in Fig. 5 and Fig. 9 means that very few bubbles are brought into this region. By contrast, relatively large bubbles are expected at the upper draft-tube region of the reactor, as coalescence prevails in this region. The largest bubbles are found in the gas-slurry separation region and also found at the upper section of the annular region. Such a result is in good agreement with the experimental measurement in a traditional bubble column as reported by Bhole et al (2008).

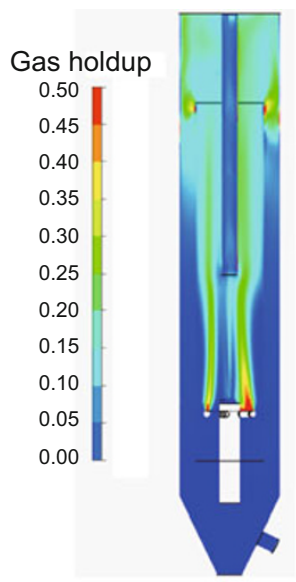

(a) $U_{\text {cir }}=0 \mathrm{~m} / \mathrm{s}$
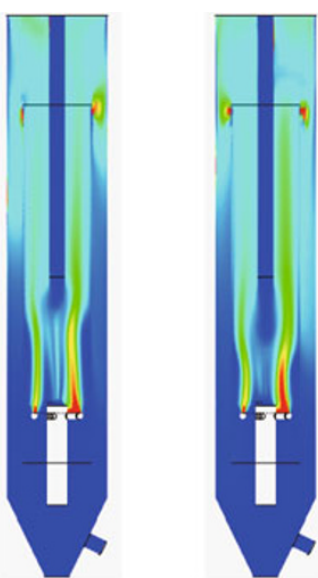

(b) $U_{\text {cir }}=0.03 \mathrm{~m} / \mathrm{s}$ (c) $U_{\text {cir }}=0.05 \mathrm{~m} / \mathrm{s}$
Fig. 8 Gas holdup distribution at different external slurry circulation velocities $\left(U_{\mathrm{g}}=0.1895 \mathrm{~m} / \mathrm{s}\right)$ 


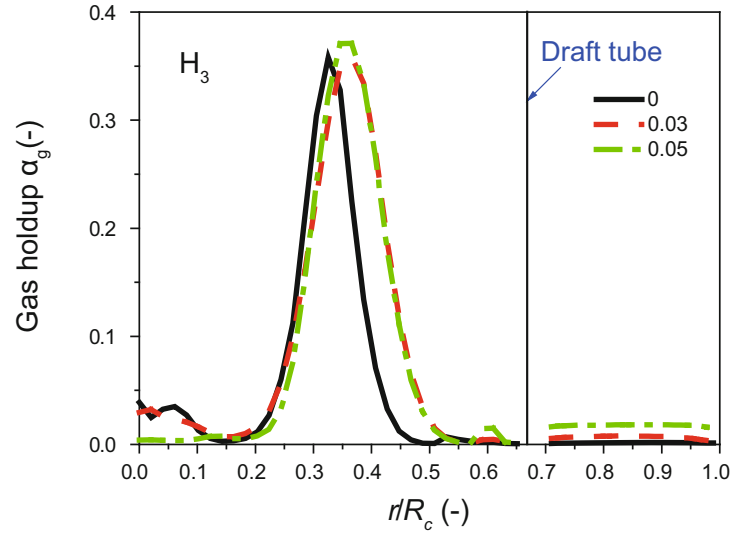

(a) Gas-distributor action region

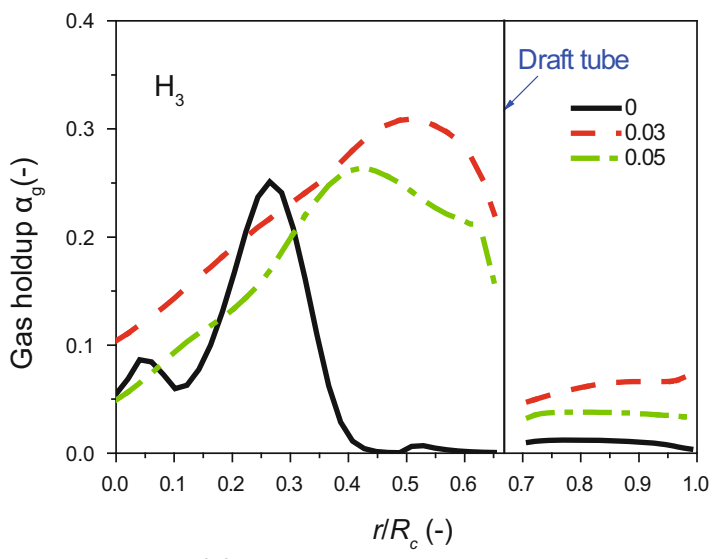

(b) Downcomer-tube action region

Fig. 9 Radial profiles of local gas holdup at different circulation velocities $\left(U_{\mathrm{g}}=0.1895 \mathrm{~m} / \mathrm{s}\right)$

\subsection{Hydrodynamics in each region}

From Figs. 5 and 10, the local gas holdup and bubble size distributions are found to be quite different in the six regions. Their hydrodynamics are discussed below.

In the bottom region: The main contribution of gas holdup in this region comes from gas bubbles brought by the circulating slurry from the annular region. As shown in Fig. $4 \mathrm{a}$, the gas holdup close to the draft tube wall is much higher than that in other radial positions. The circulating bubbles enter the bottom region along the path of the minimum resistance, and the bubbles move with the main stream flow of the slurry and change their direction of movement due to the presence of the gas distributor. Compared with Figs. $4 \mathrm{~b}$ to $4 \mathrm{e}$, the gas holdup in this region is found to be much lower than that in the annular region.

In the gas-distributor action region: In this region, the circulating bubbles are merged with the bubbles from the gas distributor. Gas bubble characteristics are largely affected by the gas distributor configuration. The maximum gas holdup is at $r / R$ from 0.3 to 0.5 , which is located above the gas jet nozzle. Inhomogeneous gas holdup distribution can be a problem in this region as the gas bubbles move as a jet out of the gas distributor and few bubbles are dispersed into the slurry phase around the gas jet.

In the downcomer-tube action region: The distribution of radial gas holdup is non-uniform for all the radial positions in Fig. $5 \mathrm{c}$, but it is more uniform than that in the gas-

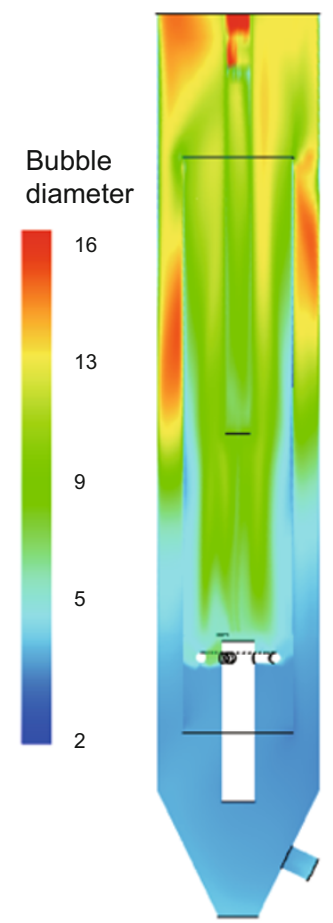

(a) $U_{\text {cir }}=0 \mathrm{~m} / \mathrm{s}$

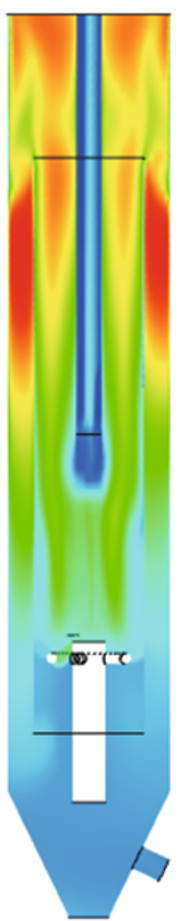

(b) $U_{\text {cir }}=0.03 \mathrm{~m} / \mathrm{s}$

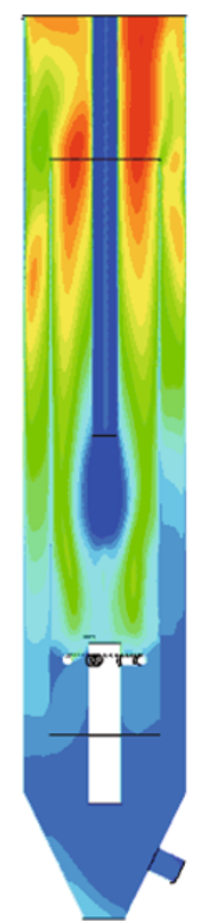

(c) $U_{\text {cir }}=0.05 \mathrm{~m} / \mathrm{s}$
Fig. 10 Bubble size distribution at different external slurry circulation velocities $\left(U_{\mathrm{g}}=0.1895 \mathrm{~m} / \mathrm{s}\right)$

distributor action region as shown in Fig. 5b. By introduction of an external slurry circulation, the inhomogeneous gas holdup distribution can be improved as shown in Fig. 9b. It can be found that the measured local holdup is higher than the predicted one in Fig. 4c. This is because that the measured gas holdup is gained from tips of the double-sensor conductivity probe, which is developed based on the assumption that all the bubbles rise vertically and are ellipsoidal with the same shape factor (Zhang et al, 2010b). However, in this highly turbulent region, gas bubbles move in different directions and turn into spherical shape as those bubbles become small.

In the upper draft-tube region: Gas bubbles move out of the downcomer-tube action region, and then enter the upper draft-tube region. These bubbles experience a similar environment as in a traditional bubble column (Jin et al, 2007). Gas holdup in the centers of the downcomer tube and draft tube is higher than that close to the draft tube wall in this region (see Figs. 5d and 5e). Gas bubbles tend to move to the centre of the internal loop section and they are larger than those in gas-distributor action region and downcomer-tube action region because coalescence of bubbles prevails in this region. As a result, the influence of either the distributor or external circulation slurry becomes weak.

In the gas-slurry separation region: When gas bubbles reach the top of the internal loop section, i.e. the gas-slurry separation region, the majority of large bubbles breakup into small ones and then escape from the gas-slurry interface. It is clearly shown that the gas holdup (Fig. 5f) in this zone at a higher gas superficial velocity $(0.0671$ to $0.1895 \mathrm{~m} / \mathrm{s})$ is almost the same as in the corresponding annular zone. By contrast, the highest gas holdup at a lower gas superficial velocity of $0.0059 \mathrm{~m} / \mathrm{s}$ (Fig. 5f) appears around the radial position of $0.6 R$. 
In the annular region: In the annular region (or outer loop), gas bubbles are brought back by the slurry phase. Gas holdup decreases from the top (Fig. 5e) to the bottom (Fig. 5b), and is much lower than that in the corresponding sections inside the draft tube as shown in Figs. $5 \mathrm{~b}$ to $5 \mathrm{e}$. Such results indicate that only small bubbles can be carried into the annular region from the gas-slurry separation region, and small bubbles coalesce to large ones when they move downward within the annular loop, and then larger bubbles change movement direction and return to the top of the annular region.

\section{Conclusion}

A coupled CFD-PBE model considering bubble breakup and coalescence characteristics is employed to investigate the hydrodynamics in the internal loop section of the combined loop reactor. Both the predicted radial profiles of local gas holdup and local mean bubble diameter are in fair agreement with our published experimental data (Zhang et al, 2010b).

Slurry circulation velocity has a significant effect on flow patterns in the downcomer-tube action region because of the interaction between the upward-moving gas bubbles and the downward-moving slurry phase. In addition, the uniformity of the radial profile of local gas holdup is greatly improved by introducing external slurry circulation from the downcomer tube, especially in the gas-distributor region, downcomer-tube action region as well as the annular region.

Local gas holdup and mean bubble diameter are quite different in different regions of the internal loop section. The local gas holdup is far lower in the bottom region than that in the other five regions. It increases dramatically in the gasdistributor action and downcomer-tube action regions, and is relatively constant in the upper draft-tube and gas-slurry separation regions. Moreover, the local gas holdup is much higher within the draft tube than that in the corresponding part of the annular region, except for the gas-slurry separation region.

The mean bubble diameter is inhomogeneously distributed in different regions. The smallest bubbles are found in the downcomer-tube action region because of the breakup of larger bubbles in the highly interactive stream, while relatively large bubbles are expected at the upper draft-tube region of the reactor as coalescence prevails in this region. The largest bubbles are found in the gas-slurry separation region and also at the upper section of the annular region.

\section{Acknowledgements}

Financial support from the National Natural Science Foundation of China (51076043 and 51061130538), Program for New Century Excellent Talents in University (NCET09-0342), Central Universities (12QN02), and 111 Project (B12034) is gratefully acknowledged. We also thank Prof. Chunxi Lu and Mr. Jin Jiaqi for their contribution in the paper.

\section{Nomenclatures}

$A_{i j} \quad$ Net interfacial area between the phases, $\mathrm{m}^{2}$
$B \quad$ Birth source, $\mathrm{kg} /\left(\mathrm{m}^{3} \cdot \mathrm{s}\right)$

$C_{\mathrm{D}} \quad$ Drag coefficient

$C_{\mathrm{TD}} \quad$ Momentum transfer coefficient for interface drag force

$C_{\varepsilon} \quad k-\varepsilon$ turbulence model constant

$C_{\mu} \quad k-\varepsilon$ turbulence model constant

$d_{b} \quad$ Mean bubble diameter, $\mathrm{m}$

$D \quad$ Death source, $\mathrm{kg} /\left(\mathrm{m}^{3} \cdot \mathrm{s}\right)$

Eö Eötvös number

$F \quad$ Size fraction

$f_{\mathrm{BV}} \quad$ Breakup fraction

$F_{\text {B }} \quad$ Calibration coefficient

$F_{i} \quad$ Total interfacial force, N

$g \quad$ Acceleration due to gravity, $\mathrm{m} / \mathrm{s}^{2}$

$g(\mathrm{~m} ; \varepsilon)$ Specific breakup rate, $1 / \mathrm{s}$

$h \quad$ Axial height of the reactor, $m$

$H \quad$ Total height of the reactor, $\mathrm{m}$

$K \quad$ Turbulence kinetic energy per unit mass, $\mathrm{m}^{2} / \mathrm{s}^{2}$

$m \quad$ Mass, $\mathrm{kg}$

$M \quad$ Morton number

$n \quad$ Number density, $1 / \mathrm{m}^{3}$

$P \quad$ Pressure, $\mathrm{Pa}$

$Q(\mathrm{~m} ; \varepsilon)$ Specific coalescence rate, $1 / \mathrm{s}$

$r \quad$ Radial position of the loop reactor, $m$

$r_{i j} \quad$ Equivalent radius, $\mathrm{m}$

$R_{c} \quad$ Radius of the loop reactor, $\mathrm{m}$

$S \quad$ Source term, $\mathrm{kg} /\left(\mathrm{m}^{3} \cdot \mathrm{s}\right)$

$T \quad$ Time, s

$u \quad$ Velocity, $\mathrm{m} / \mathrm{s}$

$U_{\text {cir }} \quad$ External slurry circulation velocity, $\mathrm{m} / \mathrm{s}$

$U_{\mathrm{g}} \quad$ Superficial gas velocity, $\mathrm{m} / \mathrm{s}$

$u_{\mathrm{T}} \quad$ The terminal velocity of bubble, $\mathrm{m} / \mathrm{s}$

$X_{i k i} \quad$ Mass fraction

\section{Greek symbol}

A Volume fraction

b Constant

$\varepsilon \quad$ Turbulence dissipation rate, $\mathrm{m}^{2} / \mathrm{s}^{3}$

$\eta_{i j} \quad$ Collision efficiency

$q \quad$ Collision frequency, $\mathrm{Hz}$

$\mu \quad$ Viscosity, $\mathrm{kg} /\left(\mathrm{m} \cdot \mathrm{s}^{2}\right)$

$\mu_{\text {ref }} \quad$ Molecular viscosity of water under a reference temperature and pressure, $\mathrm{kg} /(\mathrm{m} \cdot \mathrm{s})$

$\mu_{t g} \quad$ Gas phase kinematic eddy viscosity, $\mathrm{m}^{2} / \mathrm{s}$

$\mu_{t l} \quad$ Liquid phase kinematic eddy viscosity, $\mathrm{m}^{2} / \mathrm{s}$

$\mu_{t l, b} \quad$ Bubble-induced component of turbulent viscosity, $\mathrm{kg} /(\mathrm{m} \cdot \mathrm{s})$

$\mu_{t l, s} \quad$ Conventional shear-induced turbulent viscosity, $\mathrm{kg} /(\mathrm{m} \cdot \mathrm{s})$

$v \quad$ Kinematic viscosity, $\mathrm{m}^{2} / \mathrm{s}$

$\rho \quad$ Density, $\mathrm{kg} / \mathrm{m}^{3}$

$\sigma \quad$ Surface tension, $\mathrm{N} / \mathrm{m}$

$\sigma_{t} \quad$ Turbulent Prandtl number

$\sigma_{t l} \quad$ Liquid turbulent Schmidt number

$\sigma_{k} \quad$ Turbulence model constant for the k equation

$\sigma_{\varepsilon} \quad \mathrm{K}-\varepsilon$ turbulence model constant

$t \quad$ Actual time during the collision, $\mathrm{s}$

$\xi \quad$ Dimensionless size of eddies in the inertial

Subrange of isotropic turbulence 


\section{Subscripts \\ $b \quad$ Bubble \\ $g \quad$ Gas phase \\ $l \quad$ Liquid phase \\ $s \quad$ Solid particles \\ slurry Slurry phase}

\section{References}

ANSYS Incorporated, ANSYS CFX-Solver Release 10.0, Canada: Ansys Canada Ltd, 2005

Bartrand T A, Farouk B and Haas C N. Countercurrent gas/liquid flow and mixing: Implications for water disinfection. International Journal of Multiple Flow. 2009. 35(2): 171-184

Bhole M R, Joshi J B and Ramkrishna D. CFD simulation of bubble columns incorporating population balance modeling. Chemical Engineering Science. 2008. 63(8): 2267-2282

Clift R, Grace J R and Weber M E. Bubbles, Drops and Particles. New York: Academic Press. 1978

Deng Z H, Wang T F, Zhang N, et al. Gas holdup, bubble behavior and mass transfer in a $5 \mathrm{~m}$ high internal-loop airlift reactor with nonNewtonian fluid. Chemical Engineering Journal. 2010. 160(2): 729737

Díaz M E, Iranzo A, Cuadra D, et al. Numerical simulation of the gasliquid flow in a laboratory scale bubble column. Influence of bubble size distribution and non-drag forces. Chemical Engineering Journal. 2008. 139(2): 363-379

Giovannettone J P, Tsai E and Gulliver J S. Gas void ratio and bubble diameter inside a deep airlift reactor. Chemical Engineering Journal. 2009. 149(1-3): 301-310

Hillmer G, Weismantel L and Hofmann H. Investigations and modelling of slurry bubble columns. Chemical Engineering Science. 1994. 49(6): 837-843

Iliuta I, Larachi F, Desvigne D, et al. Multicompartment hydrodynamic model for slurry bubble columns. Chemical Engineering Science. 2008. 63(13): 3379-3399

Jia X Q, Wen J P, Zhou H L, et al. Local hydrodynamics modeling of a gas-liquid-solid three-phase bubble column. AIChE Journal. 2007. 53(9): 2221-2231

Jin H B, Yang S H, Guo Z W, et al. The axial distribution of holdups in an industrial-scale bubble column with evaluated pressure using $\gamma$-ray attenuation approach. Chemical Engineering Journal. 2005. 115(1-2): 45-50

Jin H B, Yang S H, Wang M, et al. Measurement of gas holdup profiles in a gas liquid cocurrent bubble column using electrical resistance tomography. Flow Measurement and Instrumentation. 2007. 18(5-6): 191-196

Kilonzo P M and Margaritis A. The effects of non-Newtonian fermentation broth viscosity and small bubble segregation on oxygen mass transfer in gas-lift bioreactors: a critical review. Biochemical Engineering Journal. 2004. 17(1): 27-40

Krishna R, van Baten J M and Urseanu M I Three-phase Eulerian simulations of bubble column reactors operating in the churnturbulent regime: a scale up strategy. Chemical Engineering Science. 2000. 55(16): 3275-3286

Li H and Prakash A. Heat transfer and hydrodynamics in a three-phase slurry bubble column. Industrial \& Engineering Chemistry Research. 1997. 36(11): 4688-4694

Liu M L, Zhang T W, Wang T F, et al. Experimental study and modeling on liquid dispersion in external-loop airlift slurry reactors. Chemical Engineering Journal. 2008. 139(3): 523-531

Liu M X, Lu C X, Shi M X, et al. Hydrodynamics and mass transfer in a modified three-phase airlift loop reactor. Petroleum Science. 2007.
4(3): $91-9$

Lo C S and Hwang S J. Local hydrodynamic properties of gas phase in an internal-loop airlift reactor. Chemical Engineering Journal. 2003. 91(1): 3-22

Lopez de Bertodano M. Turbulent bubbly flow in a triangular duct. Ph. D. Thesis, Rensselaer Polytechnic Institute, Troy New York. 1991

Lu C X, Qi N N, Zhang K, et al. Experiment and CFD simulation on gas holdup characteristics in an internal loop reactor with external liquid circulation. International Journal of Chemical Reactor Engineering. 2009. 7: A3

Luo H P and Al-Dahhan M H. Local characteristics of hydrodynamics in draft tube airlift bioreactor. Chemical Engineering Science. 2008. 63(11): 3057-3068

Luo S M and Svendsen H. Theoretical model for drop and bubble breakup in turbulent dispersions. AIChE Journal. 1996. 42(5): 12251233

Panneerselvam R, Savithri S and Surender G D. CFD modeling of gasliquid-solid mechanically agitated contactor. Chemical Engineering Research and Design. 2008. 86(12): 1331-1344

Prince $\mathrm{M}$ and Blanch H. Bubble coalescence and break-up in air-sparged bubble columns. AIChE Journal. 1990. 36(10): 1485-1499

Qi N N, Zhang H, Jin B, et al. CFD modelling of hydrodynamics and degradation kinetics in an annular slurry photocatalysis reactor for wastewater treatment. Chemical Engineering Journal. 2011. 172(1): $84-95$

Qi N N, Zhang K, Xu G, et al. Structure optimization of gas-liquid combined loop reactor using a CFD-PBE coupled model. Petroleum science. 2012. 9(3): 379-388

Sato $\mathrm{Y}$ and Sadatomi M. Momentum and heat transfer in two-phase bubble flow-I. International Journal of Multiple Flow. 1981. 7(2): 167-177

Talvy S, Cockx A, and Line A. Global modelling of a gas-liquid-solid airlift reactor. Chemical Engineering Science. 2005. 60(22): 59916003

Thomas D G. Transport characteristics of suspensions: a note on the viscosity of Newtonian suspensions of uniform spherical particles. Journal of Colloid and Interface Science. 1965. 20(3): 267-277

van Baten J M and Krishna R. Eulerian simulations for determination of the axial dispersion of liquid and gas phases in bubble columns operating in the churn-turbulent regime. Chemical Engineering Science. 2001. 56(2): 503-512

Vial Ch, Poncin S, Wild G, et al. Experimental and theoretical analysis of axial dispersion in the liquid phase in external-loop airlift reactors. Chemical Engineering Science. 2005. 60(22): 5945 -5954

Wang T F, Wang J F and Jin Y. Slurry Reactors for Gas-to-Liquid Processes: A Review. Industrial Engineering Chemistry Research. 2007. 46(18): 5824-5847

Zhang H, Zhang K and Fan S D. CFD simulation coupled with population balance equations for aerated stirred bioreactors. Engineering in Life Science. 2010a. 9(6): 421-430

Zhang K and Zhao Y L. A scale-up strategy for low-temperature methanol synthesis in a circulating slurry bubble reactor. Chemical Engineering Science. 2006. 61(5): 1459-1469

Zhang K, Qi N N, Jin J Q, et al. Gas holdup and bubble dynamics in a three-phase internal loop reactor with external slurry circulation. Fuel. 2010b. 89(7): 1361-1369

Zhang K, Song H S, Sun D K, et al. Low-temperature methanol synthesis in a circulating slurry bubble Reactor. Fuel. 2003. 82(2): 233-237

Zhang L J, Li T, Ying W Y, et al. Experimental study on bubble rising and descending velocity distribution in a slurry bubble column reactor. Chemical Engineering Technology. 2008. 31(9): 1362-1368

(Edited by Zhu Xiuqin) 